\title{
Composite Resin Stamping Technique using a Translucent Hot Melt Adhesive
}

\author{
Reda Mohiddin Dimashkieh
}

\begin{abstract}
Restoring a complex occlusal morphology of the posterior teeth is tremendously difficult when direct composite resin restorative materials are used because carving of the solid polymerized mass is accomplished mechanically using rotary instruments. The preoperative occlusal morphology of the tooth provides for the preparation of an ideal index of the esthetic and functional anatomy in cases where the carious lesion is confined within a shell of undermined yet intact enamel, and is registered using a transparent hot melt adhesive (HMA) material. The registration is then used as an index to reproduce the occlusal morphology in the final incremental restorative layer during the composite resin restoration, which also allows for the photopolymerization of the restoration through the translucent index.
\end{abstract}

Keywords: Clinical restorative dentistry, Composite resin, Dental restorations, Occlusion, Restorative dentistry, Stamping.

How to cite this article: Dimashkieh RM. Composite Resin Stamping Technique using a Translucent Hot Melt Adhesive. Int J Prosthodont Restor Dent 2015;5(3):63-67.

\section{Source of support: Nil}

Conflict of interest: None

\section{INTRODUCTION}

The occlusal surface of the tooth is the most susceptible to dental caries due to its complex morphology, which favors plaque accumulation leading to the decalcification and demineralization of the organic and inorganic structure of the tooth.

Advancements in direct composite resin and its ability to reduce the need to remove the sound tooth substance and mimic tooth tissues in appearance and strength make it the first (or only) choice for dentists to use for restoring posterior teeth. In most cases, patients opt for tooth-colored restorations, and it is important to be able to reproduce the occlusal morphology of the tooth accurately to maintain the original functional occlusion. Direct resin

\section{Assistant Lecturer}

Department of Oral Rehabilitation Sciences, Beirut Arab University, Beirut, Lebanon

Corresponding Author: Reda Mohiddin Dimashkieh, Assistant Lecturer, Department of Oral Rehabilitation Sciences, Beirut Arab University, Beirut, Lebanon, Phone: 0596070358, e-mail: reda_dimashkieh@hotmail.com composite restorations in posterior teeth demand several successive steps during their construction, which, if ignored, will compromise the quality of the final result. ${ }^{1}$ The ability to produce a restoration which conforms to the original occlusal form of the posterior tooth must be perceived as one of the most difficult and time-consuming goals to achieve by most dentists.

The present study describes a technique that will minimize restorative over extensions, a feature commonly observed with these types of restoration, and aid in the reproduction of the original occlusal morphology of the tooth, thereby maintaining a healthy stomatognathic system. However, such a replication technique is dependent on either a virtually intact occlusal morphology, as reported in the case of advanced hidden caries, ${ }^{2,3}$ or the presence of a desired occlusal morphology of a failed restoration. ${ }^{4}$ In many cases, the initial carious lesion presents within a shell of undermined yet intact enamel (Fig. 1). In these teeth, the preoperative occlusal morphology provides an ideal index for restitution of the esthetic and functional anatomy. ${ }^{5}$ If these conditions are met, the execution of the preoperative occlusal matrix technique can be correctly performed.

Various materials, including polyvinyl siloxane bite registration material, ${ }^{4,5}$ chemically activated acrylic resin, 6,7 and occlusal transfer devices, which are commercially available, ${ }^{8}$ have been used to create an occlusal replica of the tooth. Hot melt adhesive (HMA) is a polymer composed of ethylene-vinyl acetate (EVA) that is similar to elastomeric materials in softness and flexibility but can be processed like other thermoplastics. It is also known as hot glue and is a form of thermoplastic adhesive that is commonly supplied in solid cylindrical sticks of various diameters designed to be melted in an electric hot glue gun (Fig. 2). The gun uses a continuous-duty heating element to melt the plastic glue, which may be pushed through the gun by a mechanical trigger or directly by the user. The glue is initially hot enough to flow when squeezed out of the heated nozzle.

The glue is sticky when hot, takes a few seconds to 1 minute to solidify, and achieves full strength once cooled. The properties of the material include good clarity and gloss, stress-crack resistance, hydrophobic nature, UV resistance, nontoxic and odorless. ${ }^{9}$ 


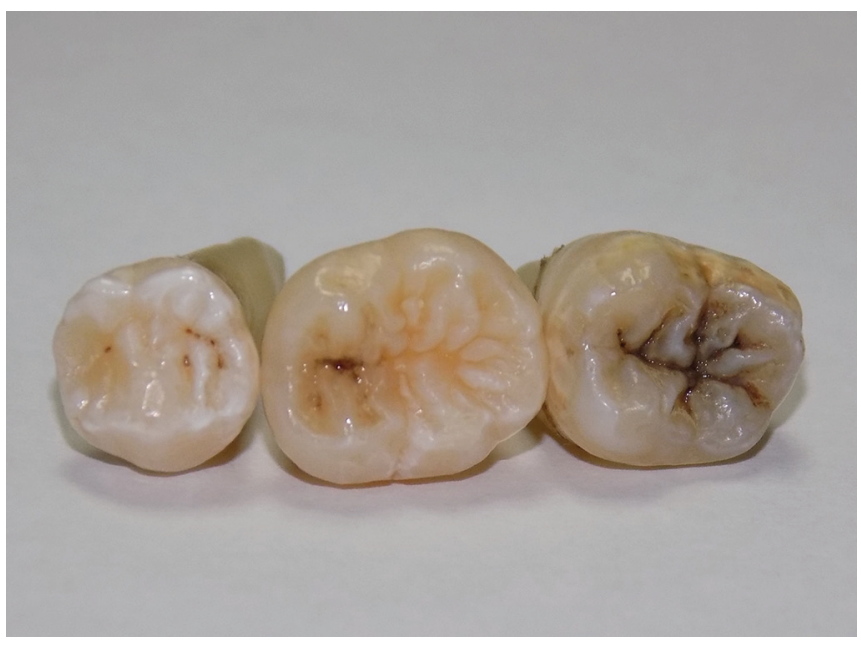

Fig. 1: Complex occlusal morphology of extracted posterior teeth

\section{MATERIALS AND METHODS}

A preoperative occlusal matrix was prepared by dispensing a small amount of the transparent HMA material from the gun onto the instrument of choice. Celluloid matrix was used to hold and carry the material to the occlusal surface, where the material was allowed to cool down and reach a dough stage (5 to 10 seconds depending on the temperature of the room; Fig. 3).

The HMA material was carried on the matrix and applied directly onto the occlusal surface of the tooth during the dough stage. The material was held in place by applying gentle pressure with a finger for at least 10 seconds while it solidifies and accurately records the anatomical features of the tooth surface; in some cases, the patient may be instructed to bite gently on the material (Figs 3 and 4).

The clear HMA index was allowed to set completely (for approximately 40 seconds) and was then removed from the tooth surface (Fig. 5A). The internal details of the index were examined (Fig. 5B).

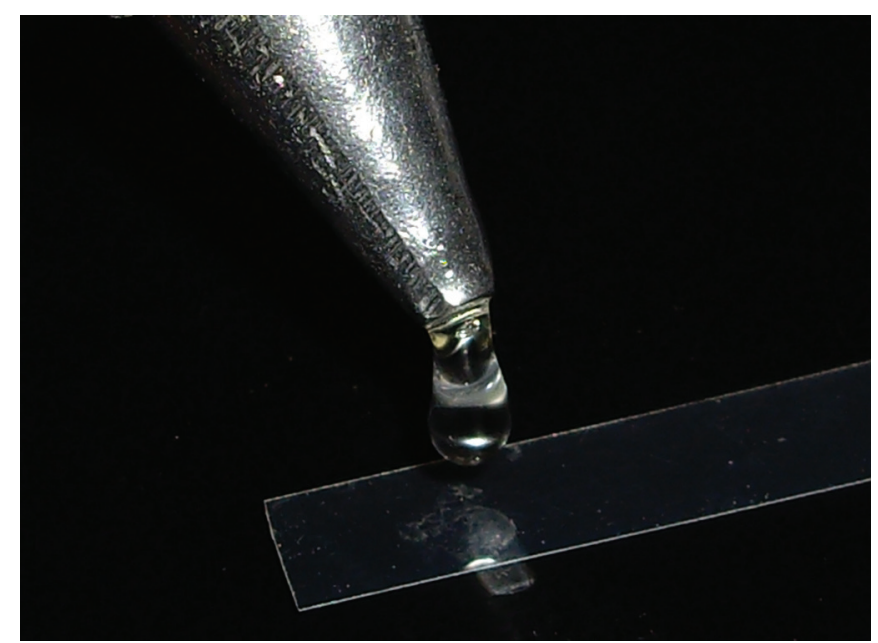

Fig. 3: Celluloid matrix used to carry the hot glue to the occlusal surface of the tooth

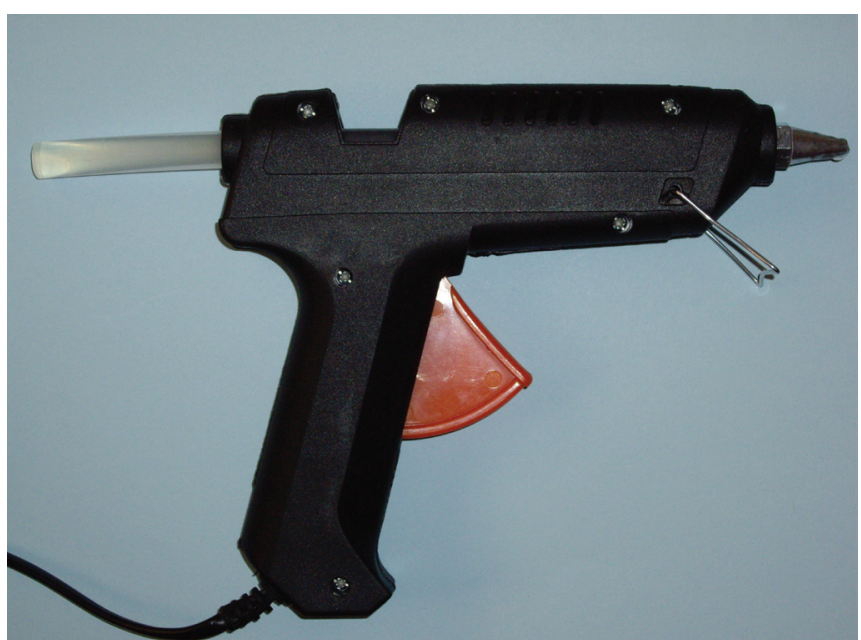

Fig. 2: An image of the hot glue gun

The tooth cavity was prepared using diamond burs (DFS-Diamon, Ländenstraße, Germany) ensuring that all decay was removed (Fig. 6). Etching and bonding of the cavity surfaces was carried out according to manufacturer's instructions (Scotchbond, 3M ESPE, USA). Lightcurable composite resin (Filtek Supreme Ultra Universal, 3M ESPE, USA) was inserted into the cavity using an incremental technique, and was light cured (Paradigm DeepCure, 3M ESPE, USA) leaving adequate space for the final increment onto which the matrix was to be placed. Leaving this final occlusal increment unpolymerized enables the HMA occlusal index to be stabilized in the original anatomic position. Subsequently, the last resin increment was polymerized across the occlusal surface by applying light on to the matrix while it is being held in position by the tip of the light cure device (Fig. 7).

After complete polymerization, the occlusal matrix was removed and the occlusal anatomy of the tooth was evaluated. The presence of excess composite material was inspected and removed with scalpel blade or a periodontal curette.

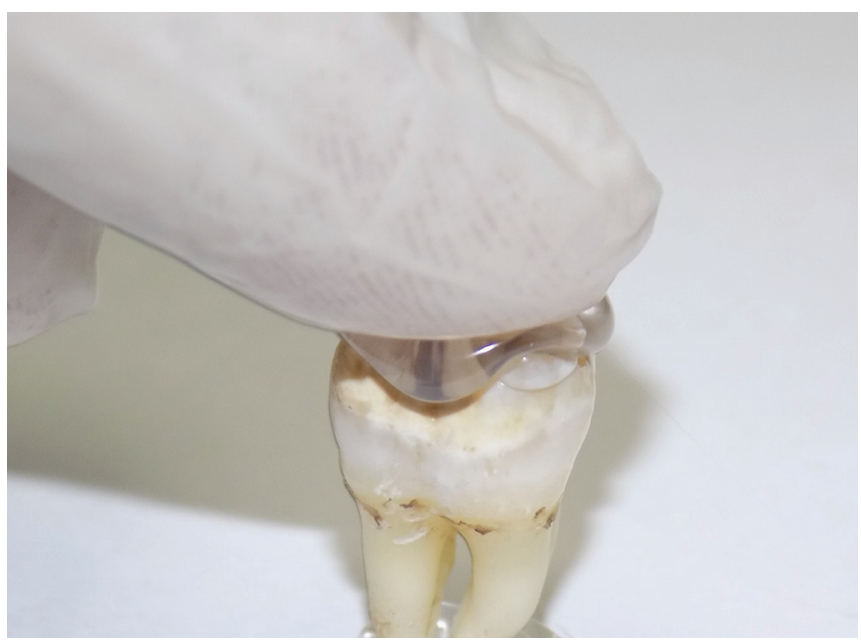

Fig. 4: The HMA was placed onto the occlusal surface of the tooth and was held using finger pressure 

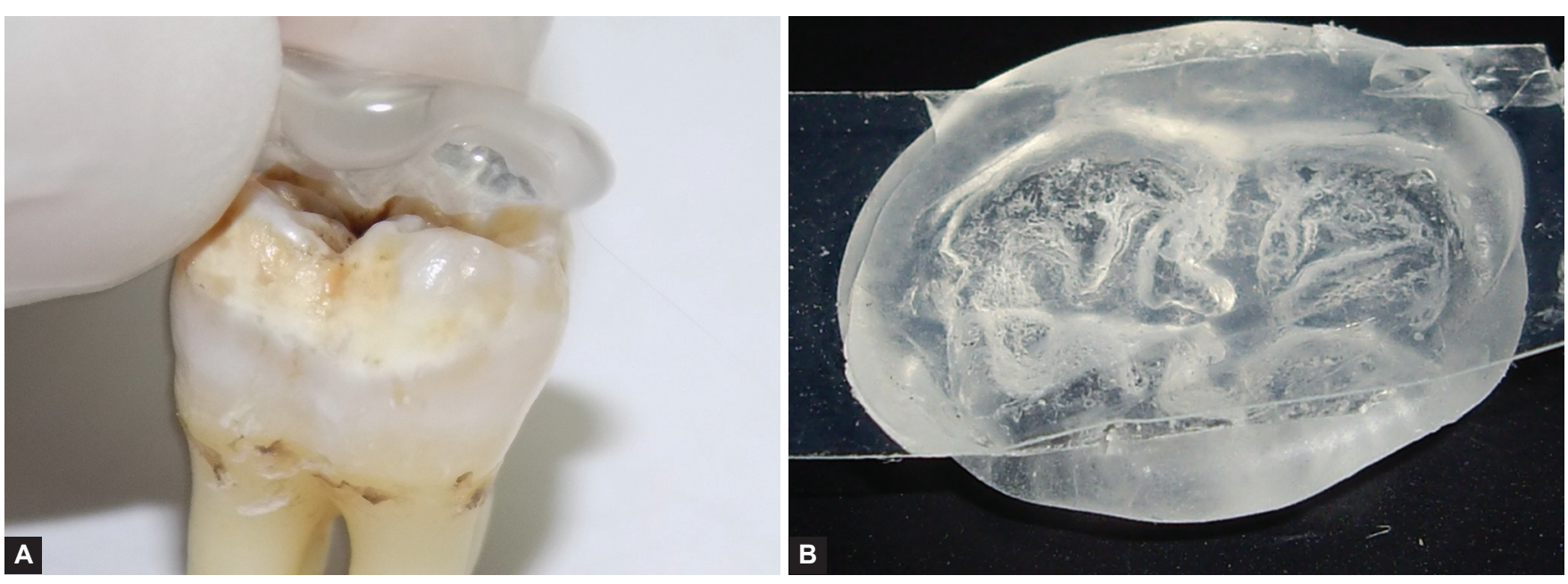

Figs $5 A$ and $B$ : The set HMA index was removed from the surface of the tooth $(A)$ and examined $(B)$

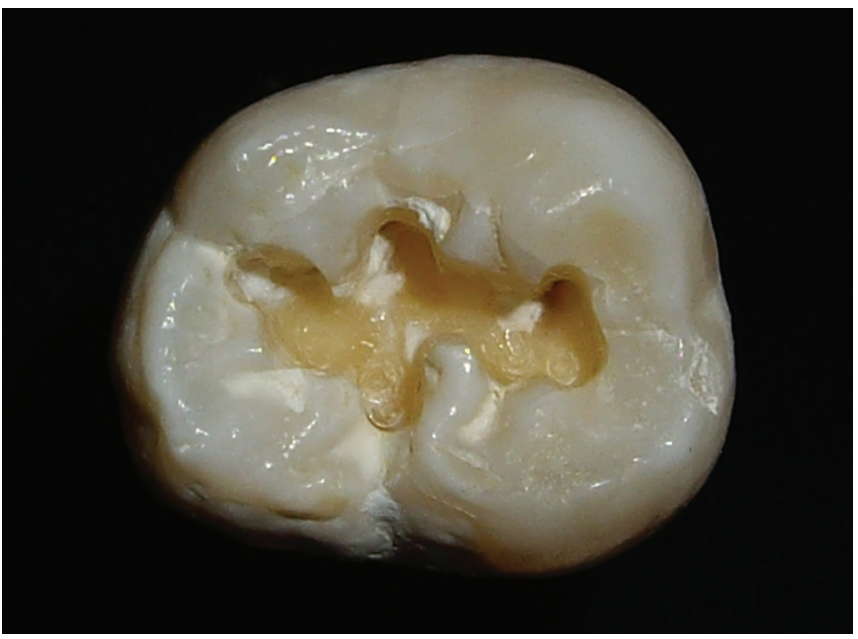

Fig. 6: Conservative cavity preparation

\section{RESULTS}

Occlusal adjustments are often not required if the anatomical morphology is completely reproduced by the occlusal replica. However, a small amount of resin removal and minor adjustments may be necessary using rubber polishers and abrasive silicon carbide instruments. Figure 8 illustrates the final appearance of the restored tooth surface.

\section{DISCUSSION}

One of the immediately evident advantages of the occlusal indexing technique is the restoration of both esthetics and function obtained with a morphology that is identical to that of the original tooth provides an excellent escape of the cusps from their fossae, thereby permitting the greatest range of interference-free motion. Therefore, this technique preserves a harmonious occlusion that follows the unique pattern of an individual's mandibular movement and is superior to all other finishing and equilibration methods, provided that the preoperative tooth morphology is accurately reproduced.

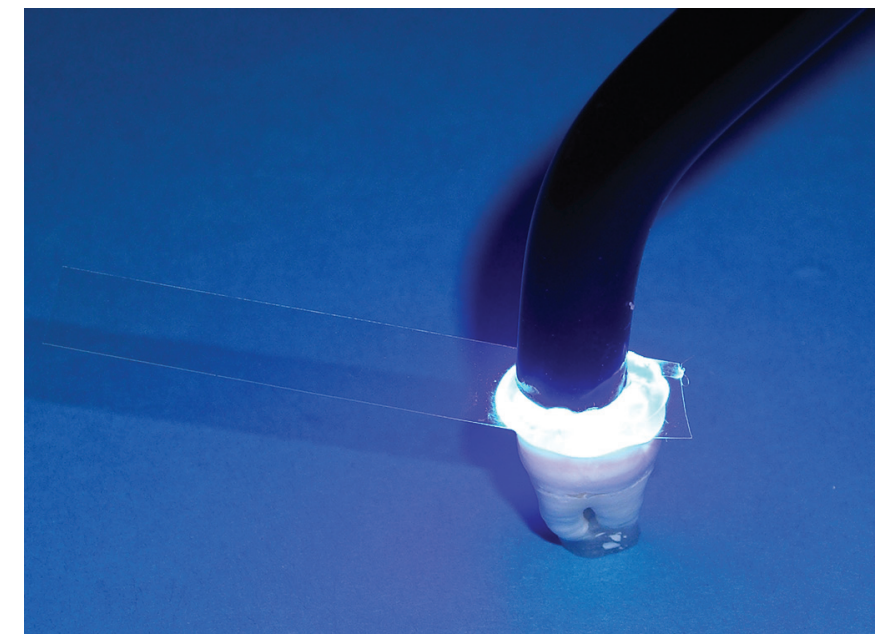

Fig. 7: Last occlusal resin composite increment polymerized through the HMA matrix

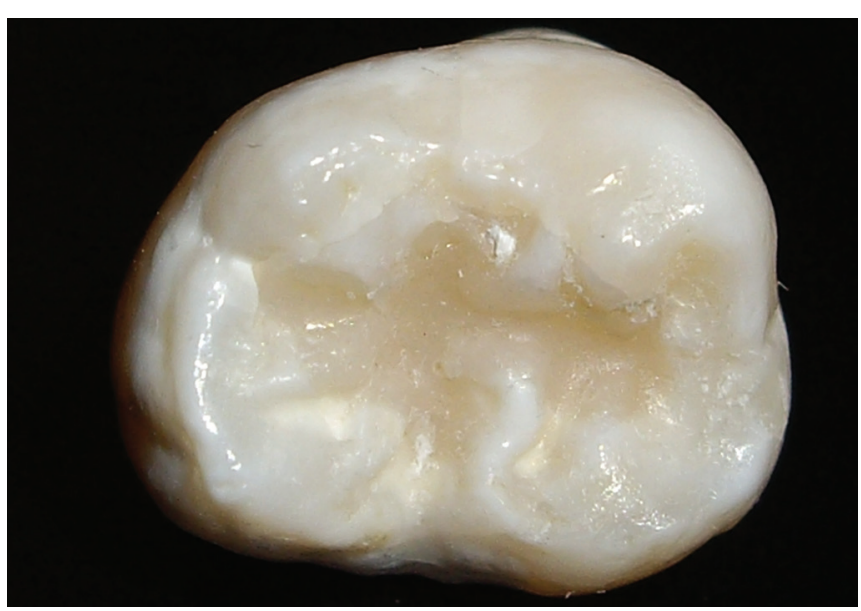

Fig. 8: Final appearance of the tooth restored with resin composite

Functional and nonfunctional occlusal adjustment of prematurities is substantially reduced or eliminated, thus reducing the time needed for finishing and polishing. The quality of placement and finishing of posterior composite resins has significant effects on the success of the procedure. It has been shown that appropriate 
finishing/polishing procedures play an important role in improving the esthetics and longevity of the dental restorations.$^{10}$ Furthermore, the superficial hardness is also expected to improve because the occlusal index isolates the resin composite from oxygen in the air, thereby ensuring optimal polymerization of the final layer. ${ }^{5}$ Even the professionals lacking in expertize will be able to carry out excellent posterior resin composite restorations.

A rise in pulp temperature is common for a variety of dental procedures. Many authors have examined changes in the pulp temperature caused as a result of cavity preparation, ${ }^{11-15}$ composite polymerization, ${ }^{16-18}$ light curing ${ }^{16,19-23}$ and bleaching. ${ }^{15,24-26}$ However, neither gutta-percha heated to $76^{\circ} \mathrm{C}^{27}$ nor hot drinks $\left(65-70^{\circ} \mathrm{C}\right)^{28}$ were shown to cause pulp damage. This may be due to the low thermal conductivity of the dentinal walls, which prevent heat dissipation through conduction. ${ }^{29}$

Due to the lack of convincing conclusions in the literature regarding the effect of high temperatures on pulpal damage, it is better to avoid marked increases in temperature during dental procedures. However, one study in rhesus monkeys demonstrated pulp irreversibility in $15 \%$ of the teeth by increasing the temperature to $5.6^{\circ} \mathrm{C}$; another study reported no changes in pulp pathology when intrapulpal temperatures were increased by 8.9 to $14.7^{\circ} \mathrm{C}$ in humans. ${ }^{30,31}$

At the dough stage, the temperature of the HMA material is not very high (allowing for manipulation using fingertips); therefore, it should safe for use on the tooth without causing any irreversible pulp damage.

\section{CONCLUSION}

Numerous techniques have been introduced for restoration and reproduction of the occlusal morphology of a carious tooth where the lesion is confined within a shell of undermined yet intact enamel. Besides substantially simplifying the placement of resin composite restorations onto the occlusal surfaces of posterior teeth, this technique accelerates treatment using available HMA (stamping) material and represents a highly efficient practical procedure that will optimize the quality and success of posterior tooth-colored restorations if correctly employed.

\section{CLINICAL RELEVANCE}

The use of HMA material as an occlusal index for composite resin stamping is considered as a new technique that is feasible to adopt and opens up new avenues of research with regard to the testing and application of this promising industrial material. This technique can be used in different restorative procedures for posterior and anterior teeth.

\section{REFERENCES}

1. Schlichting LH, Monteiro S Jr, Baratieri LN. A new proposal to optimize the occlusal margin in direct resin composite restorations of posterior teeth. European J Esthetic Dentis 2007;3(4):348-360.

2. Ricketts D, Kidd E, Weerheijm K, Soet H. Hidden caries: What is it? Does it exist? Does it matter? Int Dent J 1997;47(5): 259-265.

3. Trevisan TC, de Andrade MC, Presoto CD. Hidden caries: a critical review. Scienti J Dentis 2015;2(1):33-36.

4. Geddes A, Craig J, Chadwick R. Preoperative occlusal matrix aids the development of occlusal contour of posterior occlusal resin composite restorations-clinical rationale and technique. British dent J 2009;206(6):315-317.

5. Liebenberg WH. Occlusal index-assisted restitution of esthetic and functional anatomy in direct tooth-colored restorations. Quintessence Int 1996;27(2):81-88.

6. Baratieri LN, Monteiro JS, Correa M, Ritter AV. Posterior resin composite restorations: a new technique. Quintessence Int 1996;27(11):733-738.

7. Baratieri LN, Monteiro JJ, de Andrada M, Aracari G. Composite resin veneers: a new technique. Quintessence Int 1992;23(4):237-243.

8. Martos J, Silveira L, Ferrer-Luque CM, González-López S. Restoration of posterior teeth using occlusal matrix technique. Indian J Dent Res 2010;21(4):596.

9. Hot-melt adhesive. (2015 AIW, The Free Encyclopedia. Retrieved 11:37, June 15, 2015. Available at: https// en.wikipedia.org/w/index.php?title=Hot-melt_adhesive \&oldid $=654685719$.

10. Ece E, Cogulu D, Attin T. The effect of finishing and polishing systems on surface roughness, microhardness and microleakage of a nanohybrid composite. J Int Dent Med Res 2012;5(3):155-160.

11. Cavalcanti BN, Lage-Marques JL, Rode SM. Pulpal temperature increases with Er:YAG laser and high-speed handpieces. J Prosthet Dentis 2003;90(5):447-451.

12. Cavalcanti BN, Otani C, Rode SM. High-speed cavity preparation techniques with different water flows. J Prosthet Dentis 2002;87(2):158-161.

13. Mollica FB, Camargo FP, ZamboniSC, Pereira SMB, Teixeira SC, Nogueira Junior L. Pulpal temperature increase with highspeed handpiece, Er:YAG laser and ultrasound tips. J Appl Oral Sci 2008;16(3):209-213.

14. Firoozmand L, Faria R, Araujo M, Di Nicoló R, Huthala M. Temperature rise in cavities prepared by high and low torque handpieces and Er:YAG laser. British Dent J 2008;205(1):28-29.

15. Öztürk B, Üşümez A, Öztürk AN, Ozer F. In vitro assessment of temperature change in the pulp chamber during cavity preparation. J Prosthet Dentis 2004;91(5):436-440.

16. Baroudi K, Silikas N, Watts DC. In vitro pulp chamber temperature rise from irradiation and exotherm of flowable composites. Int J Paediat Dentist 2009;19(1):48-54.

17. Chiodera G, Gastaldi G, Millar BJ. Temperature change in pulp cavity in vitro during the polymerization of provisional resins. Dent Materials 2009;25(3):321-325.

18. Daronch M, Rueggeberg FA, Hall G, Mario F. Effect of composite temperature on in vitro intrapulpal temperature rise. Dent Materials 2007;23(10):1283-1288. 
19. Bagis B, Bagis $Y$, Ertas E, Ustaomer S. Comparison of the heat generation of light curing units. J Contempor Dent Pract 2008;9(2):65-72.

20. Durey K, Santini A, Miletic V. Pulp chamber temperature rise during curing of resin-based composites with different light-curing units. Primary Dental Care 2008;15(1):33-38.

21. Guiraldo RD, Consani S, Sinhoreti MAC, Correr-Sobrinho L, Schneider LFJ. Thermal variations in the pulp chamber associated with composite insertion techniques and lightcuring methods. J Contempor Dent Pract 2009;10(1):17-24.

22. Gomes Silva PC, Lizarelli RDFZ, Moriyama LT, Porto Neto SDT, Bagnato VS. Temperature analysis during bonding of brackets using LED or halogen light base units. Photomed Laser Therapy 2005;23(1):41-46.

23. Uzel A, Buyukyilmaz T, Kayalioglu M, Uzel I. Temperature rise during orthodontic bonding with various light-curing units-an in vitro study. The Angle Orthodontist 2006;76(2): 330-334.

24. Carrasco TG, Carrasco-Guerisoli LD, Fröner IC. In vitro study of the pulp chamber temperature rise during light-activated bleaching. J Appl Oral Sci 2008;16(5):355-359.
25. Eldeniz AU, Usumez A, Usumez S, Ozturk N. Pulpal temperature rise during light-activated bleaching. J Bio Med Materials Res Part B: Applied Biomaterials 2005;72(2):254-259.

26. Kabbach W, Zezell DM, Pereira TM, Albero FG, Clavijo VRG, de Andrade MF. A thermal investigation of dental bleaching in vitro. Photomed Laser Surg 2008;26(5):489-493.

27. Goodis HE, Schein B, Stauffer P. Temperature changes measured in vivo at the dentinoenamel junction and pulpodentin junction during cavity preparation in the Macaca fascicularis monkey. J Endodont 1988;14(7):336-339.

28. Mank S, Steineck M, Brauchli L. Influence of various polishing methods on pulp temperature. J Orofac Orthoped/Fortschritte der Kieferorthopädie 2011;72(5):348-357.

29. Kodonas K, Gogos C, Tziafas D. Effect of simulated pulpal microcirculation on intrapulpal temperature changes following application of heat on tooth surfaces. Int Endodon J 2009;42(3):247-252.

30. Zach L, Cohen G. Pulp response to externally applied heat. Oral Surg Oral Med Oral Pathol 1965;19(4):515-530.

31. Baldissara P, Catapano S, Scotti R. Clinical and histological evaluation of thermal injury thresholds in human teeth: a preliminary study. J Oral Rehabilitation 1997;24(11):791-801. 